\title{
Les écritures migrantes. De l'exil à la migrance littéraire dans le roman francophone, éds. Adama Coulibaly, Yao Louis Konan
}

\section{Emanuela Cacchioli}

\section{(2) OpenEdition Journals}

\section{Edizione digitale}

URL: http://journals.openedition.org/studifrancesi/5448

DOI: $10.4000 /$ studifrancesi.5448

ISSN: 2421-5856

\section{Editore}

Rosenberg \& Sellier

\section{Edizione cartacea}

Data di pubblicazione: 1 dicembre 2016

Paginazione: 569-570

ISSN: 0039-2944

\section{Notizia bibliografica digitale}

Emanuela Cacchioli, « Les écritures migrantes. De l'exil à la migrance littéraire dans le roman francophone, éds. Adama Coulibaly, Yao Louis Konan », Studi Francesi [Online], 180 (LX | III) | 2016, online dal 01 janvier 2017, consultato il 18 septembre 2020. URL : http://journals.openedition.org/studifrancesi/ 5448 ; DOI : https://doi.org/10.4000/studifrancesi.5448

\section{Questo documento è stato generato automaticamente il 18 settembre 2020.}

\section{cc) $($ ) $\ominus$}

Studi Francesi è distribuita con Licenza Creative Commons Attribuzione - Non commerciale - Non opere derivate 4.0 Internazionale. 


\title{
Les écritures migrantes. De l'exil à la migrance littéraire dans le roman francophone, éds. Adama Coulibaly, Yao Louis Konan
}

\author{
Emanuela Cacchioli
}

\section{NOTIZIA}

Les écritures migrantes. De l'exil à la migrance littéraire dans le roman francophone, sous la direction de Adama Coulibaly, Yao Louis KonAN, Paris, L'Harmattan, 2015, 256 pp.

1 La raccolta di saggi, diretta da Adama Coulibaly e Yao Louis Konan, affronta il tema delle scritture migranti, ossia della letteratura che si costruisce attorno alle nozioni di movimento, transizione, transito, spostamento, trasferimento. Attraverso tali suggestioni non si intende solo la mobilità di persone, ma anche di oggetti e soprattutto di idee. Uno dei possibili paradigmi che viene spesso evocato a tal proposito è l'«entredeux», il quale è generalmente studiato a partire dalle tre tappe essenziali che la migrazione implica: il trauma della partenza, il trasferimento e l'integrazione nel paese di arrivo. Gli articoli riuniti in questo volume intendono dimostrare che la riflessione è più complessa: la nozione di migrazione non corrisponde semplicemente all'esilio $\mathrm{e}$ varia tra gli autori di prima e di seconda generazione. Anche all'interno di tale bipartizione permangono ulteriori differenze tra gli scrittori. Le prime forme di scrittura migrante sono «résolument tournés vers l'essentialisation du pays natal et l'authenticité» (p. 8) e offrono una rappresentazione de «l'immigration contemplative et moralisatrice» (p. 8). Gli autori non sono ancora aperti all'idea di una scrittura migrante e, secondo i curatori del volume, privilegiano l'ottica dell'immigrazione. Sono inseriti in questa categoria i testi di Ousmane Socé e Bernard Dadié. Gli scrittori della seconda generazione, invece, evocano sia la Francia, sia il paese d'origine e si focalizzano sul fatto di essere stranieri in terra europea. Lo schema tripartito 
dell'«entre-deux» si arricchisce, dunque, della questione della metamorfosi dell'identità che non si limita più soltanto ad una riflessione sull'integrazione nel paese d'accoglienza, ma converge su una complessità e un'ambiguità che permettono agli autori di trattare i temi de «la mouvance identitaire et culturelle, de l'hybridité ou du métissage identitaire» (p. 10). Negli ultimi quindici anni, gli scrittori francofoni si sono dedicati a problematiche generali che hanno spesso implicato uno spostamento dell'interesse dalla loro terra natale a una prospettiva più ampia e non limitata ai confini geografici. Diventa arduo il compito degli studiosi che intendono trovare un'etichetta in grado di riunire gli autori in base al criterio dell'immigrazione, in quanto esso non è sempre il focus delle scritture migranti. Coulibaly e Konan propongono, dunque, di considerare la dimensione discorsiva ed estetica: le forme e i discorsi che proliferano nelle scritture migranti sono il filo conduttore degli articoli inseriti nel presente volume. La raccolta si apre con il contributo di Adama CoUlibALY, Esquisses d'une problématique de l'écriture migrante dans le roman... ivoirien (pp. 19-48), il quale analizza quattro romanzi di Véronique Tadjo, Koffi Kwahulé, Werewere Liking e Maurice Bandaman dal punto di vista socio-testuale e socio-critico. Lo studioso evidenzia che i concetti di stato e di confine nazionale non sono operativi nel contesto delle scritture migranti. L'articolo di Didier Brou ANOH, Poétiques des écritures migrantes dans "Le Roi de Kahel" de Tierno Monénembo (pp. 49-64), si concentra su un altro elemento fondamentale della scrittura migrante: la ricerca identitaria. Nel romanzo esaminato, il critico rintraccia la combinazione di segni culturali differenti legati sia al paese di origine che a quello di accoglienza e propone una riflessione sulla scelta della lingua da adottare. Elisabetta BEVILACQUA, Écritures migrantes de quelques pieds-noirs d'Algérie: le cas de Marie Cardinal et d'Alain Vircondelet (pp. 65-85), sposta la sua attenzione al Maghreb. La studiosa sostiene l'ipotesi che la letteratura dei «pieds-noirs» d'Algeria possa essere inserita tra le scritture migranti, in quanto le dinamiche e le tematiche dell'erranza e dell'«entre-deux» identitario possono essere facilmente ricondotte a tale ambito. Il contributo di Antonin ZIGOLI, "Le Ventre de l'Atlantique" et "La Préférence nationale" de Fatou Diome: deux cuvres paradigmatiques de l'écriture migrante (pp. 87-108), mette in luce come la difficoltà di inserimento in Europa da parte dell'autrice senegalese le abbia permesso di passare dalla condizione di vittima ad un'apertura all'interculturalità. L'identità transitoria, aperta, flessibile in un'ottica di relazione dovuta all'esilio e al conseguente sradicamento e nuovo insediamento nel paese straniero sono i temi affrontati da Roger TRO DÉHO nel suo contributo dal titolo: L'écriture migrante comme poétique de l'"oikos": une lecture de "Rift routes rails" et "Transit" d'Abdourahman Waberi (pp. 109-139). Anna LAPETINA, Au-delà des lisières: mobilité et problématiques identitaires dans les romans de Nancy Huston (pp. 141-157), offre al lettore un'analisi delle opere della scrittrice al fine di mettere in evidenza come ogni spostamento implichi anche un superamento del confine intimo e una conseguente scoperta di se stessi. L'analisi delle opere di Gisèle Pineau consente a Yannick LEMKI, Écriture migrante et quête identitaire dans les œuvres de Gisèle Pineau (pp. 159), di indagare la tensione che si crea tra l'«ici», ossia la Francia, e l'«ailleurs», la Guadalupa. Non si realizza una dicotomia tra i due poli, ma si stabilisce quel dialogo interculturale proprio della letteratura postcoloniale. Lo stesso discorso prosegue idealmente nel contributo di Yao Louis KONAN, D'un débat... autour de l'écriture migrante dans "Le Ventre de l'Atlantique" de Fatou Diome et "Le Paradis français" de Maurice Bandaman (pp. 183-210). A partire dalle stesse categorie, lo studioso mette in luce come le opere di Diome e Bandaman siano portatrici di due visioni opposte: il primo autore può essere ascritto alla seconda generazione degli scrittori migranti, mentre il secondo 
privilegia il recupero delle origini in un'ottica contemplativa e poco dinamica. Chiude la raccolta l'articolo di Siham BOUAMER, "Lettres parisiennes": de l'exil à la migrance (pp. 211-234), in cui il critico propone la visione di Leïla Sebbar. L'autrice considera l'identità in movimento con uno sguardo positivo, in quanto diviene un modo per superare le difficoltà dell'esilio e conciliare le varie identità attraverso la scrittura.

2 L'aspetto principale che accomuna gli articoli riuniti in questo volume è, dunque, quello dell'identità, intesa come un'entità dinamica costretta a ridefinirsi per accettare e integrare gli aspetti culturali del paese di arrivo. Gli autori non dimenticano la terra natale, ma il contatto con una nuova realtà rende necessario il processo di riconfigurazione della propria identità. La letteratura diviene un terreno fertile in cui è possibile rendere conto e dare forma all'essere umano nuovo che, per varie ragioni, vive in esilio. Tale riconfigurazione assume appunto forme originali e scaturisce in riflessioni molto diverse tra loro. La presente raccolta di saggi si inserisce nel filone delle scritture migranti e va ad arricchire le già numerose pubblicazioni che negli ultimi anni hanno affrontato questo aspetto dell'opera letteraria. 